\title{
Simultaneous Spectrophotometric Estimation of Artesunate and Mefloquine
}

\author{
T. M. Kalyankar, ${ }^{1}$ R. B. Kakade, ${ }^{2}$ M. S. Attar, ${ }^{1}$ and A. R. Kamble ${ }^{1}$ \\ ${ }^{1}$ Department of Pharmaceutical Chemistry, School of Pharmacy, Swami Ramanand Teerth Marathwada University, \\ Vishnupuri, Nanded 431606, India \\ ${ }^{2}$ Department of Pharmaceutical Sciences, R. T. M. Nagpur University, Nagpur 440010, India
}

Correspondence should be addressed to T. M. Kalyankar; dr.kalyankartm@gmail.com

Received 21 June 2012; Accepted 27 September 2012

Academic Editor: Benoit Braïda

Copyright (c) 2013 T. M. Kalyankar et al. This is an open access article distributed under the Creative Commons Attribution License, which permits unrestricted use, distribution, and reproduction in any medium, provided the original work is properly cited.

\begin{abstract}
A simple, rapid, precise, and accurate UV-visible spectrophotometric method has been developed for the simultaneous determination of Artesunate in combination with Mefloquine. For developing the method, methanol was used as a solvent. Artesunate and Mefloquine showed $\lambda_{\max }$ at $240 \mathrm{~nm}$ and $222 \mathrm{~nm}$, respectively. The proposed method was validated as per ICH guideline. The linearity range of Artesunate and Mefloquine were 10-60 and 20-120 $\mu \mathrm{g} / \mathrm{mL}$, respectively. $99.91 \pm 0.2740$ and $99.56 \pm 0.2067$ these value represent the percent recovery of Artesunate and Mefloquine respectively The correlation coefficients of Artesunate and Mefloquine were 0.999, and 0.999, respectively. The relative standard deviation for six replicates was always less than $2 \%$. The statistical analysis proves that the method is suitable for the analysis of Artesunate and Mefloquine as the bulk drugs and in pharmaceutical formulation without any interference from the excipients.
\end{abstract}

\section{Introduction}

A simple, rapid, precise, and accurate UV-visible spectrophotometric method has been developed for the simultaneous determination of Artesunate in combination with Mefloquine. ART and MEF are poorly water soluble drugs; therefore, methanol was used as a solvent as it is completely soluble in it. Methanol did not interfere in the spectroscopic determination of ART and MEF having maximum absorbance at $240 \mathrm{~nm}$ and $222 \mathrm{~nm}$, respectively.

Chemically Artesunate is $(3 \mathrm{R}, 5 \mathrm{aS}, 6 \mathrm{R}, 8 \mathrm{aS}, 9 \mathrm{R}, 10 \mathrm{~S}, 12 \mathrm{R}$, 12aR)-Decahydro-3,6,9 trimethyl-3,12-epoxy-12H-pyrano [4,3-j]-1,2benzodioxepin-10-ol, hydrogen succinate, while Mefloquine is DL-erythro-\&alpha;-2-piperidyl-2,8-bis(trifluoromethyl)-4quinolinemethanol monohydrochloride; ( $\mathrm{R}^{*}$, $\left.S^{*}\right)-( \pm)$-\& alpha;-2-piperidinyl-2,8-bis(trifluoromethyl)-4quinolinemethanol monohydrochloride. Structures of ART and MEF are shown in Figure 1. Artesunate and its active metabolite dihydroartemisinin are potent blood schi zonticides, active against the ring stage of the parasite.
Artesunate is ideal for the treatment of severe malaria, including cerebral malaria $[1,2]$.

Standard drug sample of Artesunate and Mefloquine was pursued as a gift sample from Cipla Ltd. and Macleoids Ltd. All chemicals and solvents of AR grade were purchased from Qualigens fine Chemicals, Mumbai, India.

UV-spectrophotometer UV-1800 (Shimadzu, Japan) with spectral bandwidth of $2 \mathrm{~nm}$ and $10 \mathrm{~mm}$ matched quartz cells were used for the development analytical method over the range of 200-400 nm. Marketed formulation Falcigo Plus tablet containing ART $100 \mathrm{mg}$ and MEF $200 \mathrm{mg}$ was used as sample, purchased from local market. Calibrated glassware was used throughout the work.

\section{Experimental}

2.1. Preparation of Standard Stock Solutions. An accurately weighed quantity of about $10 \mathrm{mg}$ of pure drug of ART was dissolved in methanol and diluted to $100 \mathrm{~mL}$. (Concentration $100 \mu \mathrm{g} / \mathrm{mL}$ ). 


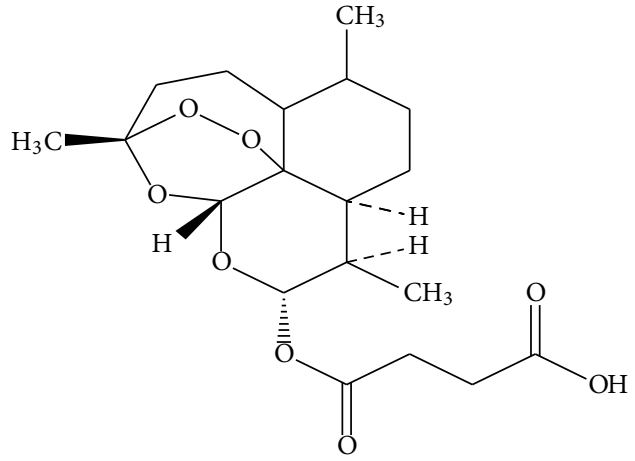

(a)

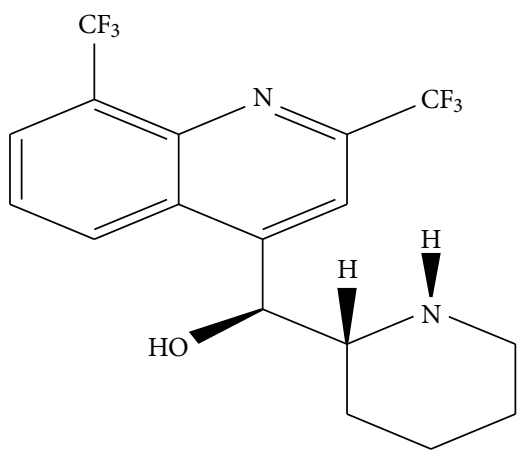

(b)

Figure 1: (a) Structure of Artesunate and (b) structure of Mefloquine.

TABLE 1: Standard calibration table for ART and MEF.

\begin{tabular}{lcccc}
\hline \multirow{2}{*}{ Sr. no. } & \multicolumn{2}{c}{ For Artesunate } & \multicolumn{2}{c}{ For Mefloquine } \\
& Conc. $(\mu \mathrm{g} / \mathrm{mL})$ & Abs. $^{*}$ at $240 \mathrm{~nm}$ & Conc. $(\mu \mathrm{g} / \mathrm{mL})$ & 20 \\
Abs. ${ }^{*}$ at $222 \mathrm{~nm}$ \\
\hline$(1)$ & 10 & 0.037 & 40 & 0.132 \\
$(2)$ & 20 & 0.07 & 60 & 0.28 \\
$(3)$ & 30 & 0.107 & 80 & 0.397 \\
$(4)$ & 40 & 0.139 & 100 & 0.548 \\
$(5)$ & 50 & 0.175 & 120 & 0.676 \\
$(6)$ & 60 & 0.208 & 0.796 \\
\hline
\end{tabular}

${ }^{*}$ Each value is a mean of six observations.

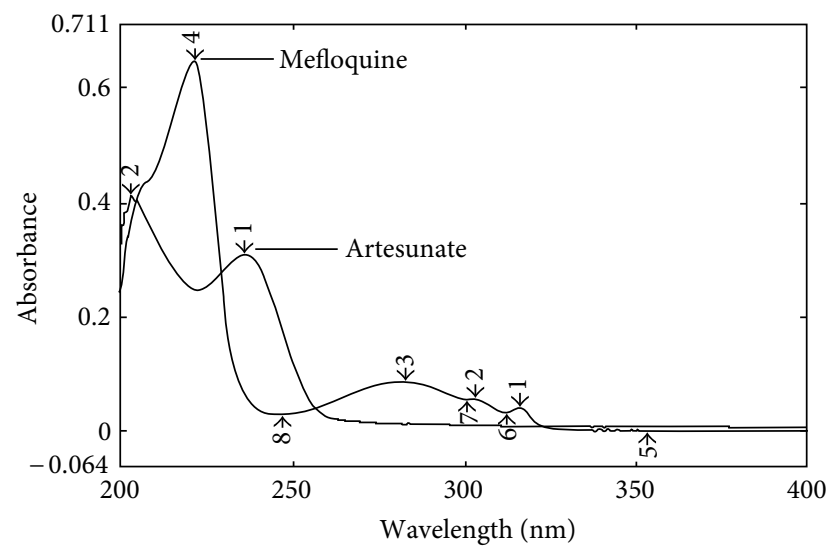

FIgURE 2: Overlay spectrum of the ART and MEF.

Similarly, accurately weighed quantity of about $20 \mathrm{mg}$ of pure drug of MEF was dissolved in methanol and diluted to $100 \mathrm{~mL}$. (Concentration $200 \mu \mathrm{g} / \mathrm{mL}$ ).

2.2. Selection of Analytical Wavelengths. Appropriate dilutions were prepared for each drug from the standard stock solution and scanned in the spectrum mode from $400 \mathrm{~nm}$ to $200 \mathrm{~nm}$. ART and MEF showed absorbance maxima at $240 \mathrm{~nm}$ (Figure 2) and at $222 \mathrm{~nm}$ (Figure 3), respectively. Figure 4 represents the overlay spectra for ART and MEF.
TABLE 2: Optical characteristics and other parameters.

\begin{tabular}{lcc}
\hline Parameters & ART & MEF \\
\hline Working wavelength $(\mathrm{nm})$ & 240 & 222 \\
Linearity range $(\mu \mathrm{g} / \mathrm{mL})$ & $10-60$ & $20-120$ \\
Molar absorptivity & 3.7 & 6.6 \\
Limit of detection $(\mu \mathrm{g} / \mathrm{mL})$ & 0.54 & 0.45 \\
Limit of quantitation $(\mu \mathrm{g} / \mathrm{mL})$ & 1.79 & 1.48 \\
$Y=m x+c$ & 0.003 & 0.006 \\
Slope & 0.0001 & 0.0003 \\
Intercept & 0.999 & 0.998 \\
Regression coefficient & & \\
\hline
\end{tabular}

2.3. Selection of Analytical Concentration Ranges. From the standard stock solution of ART, appropriate aliquots were pipetted out into $10 \mathrm{~mL}$ volumetric flasks and dilutions were made with methanol to obtain working standard solutions of concentrations $10-60 \mu \mathrm{g} / \mathrm{mL}$. Absorbance for these solutions were measured at $240 \mathrm{~nm}$ (Table 1) and a calibration curve of absorbance against concentration was plotted as shown in (Figure 3).

Similarly, a series of standard solutions of concentration $20-120 \mu \mathrm{g} / \mathrm{mL}$ were prepared for MEF and their absorbance was measured at $222 \mathrm{~nm}$ (Table 1). A standard calibration curve of absorbance against concentration was plotted (Figure 4). Both drugs followed the Beers-Lamberts law in the range of $10-60 \mu \mathrm{g} / \mathrm{mL}$ and $20-120 \mu \mathrm{g} / \mathrm{mL}$ for ART and MEF, 
TABLE 3: Absorbance of mixed standards containing ART and MEF.

\begin{tabular}{lcccc}
\hline Sr. no. & \multicolumn{2}{c}{ Mixed Standards } & Abs. at 240 $\mathrm{nm}$ & \multirow{2}{*}{ Abs. at 222 $\mathrm{nm}$} \\
\hline$(1)$ & Conc. of ART $(\mu \mathrm{g} / \mathrm{mL})$ & Conc. of MEF $(\mu \mathrm{g} / \mathrm{mL})$ & 0.039 & 0.134 \\
$(2)$ & 10 & 20 & 0.112 & 0.399 \\
$(3)$ & 30 & 60 & 0.204 & 0.790 \\
\hline
\end{tabular}

TABLE 4: Results of mixture containing ART and MEF.

\begin{tabular}{|c|c|c|c|c|c|c|}
\hline \multirow{2}{*}{ Sr. no. } & \multicolumn{2}{|c|}{ Amount present ${ }^{*}(\mu \mathrm{g} / \mathrm{mL})$} & \multicolumn{2}{|c|}{ Amount found $^{*}(\mu \mathrm{g} / \mathrm{mL})$} & \multicolumn{2}{|c|}{ \% Amount found ${ }^{*}$} \\
\hline & ART & MEF & ART & MEF & ART & MEF \\
\hline (1) & 10 & 20 & 9.98 & 19.89 & 99.80 & 99.45 \\
\hline (2) & 30 & 60 & 29.85 & 59.76 & 99.50 & 99.60 \\
\hline (3) & 60 & 120 & 59.93 & 119.65 & 99.88 & 99.70 \\
\hline
\end{tabular}

${ }^{*}$ Each value is a mean of six observations.

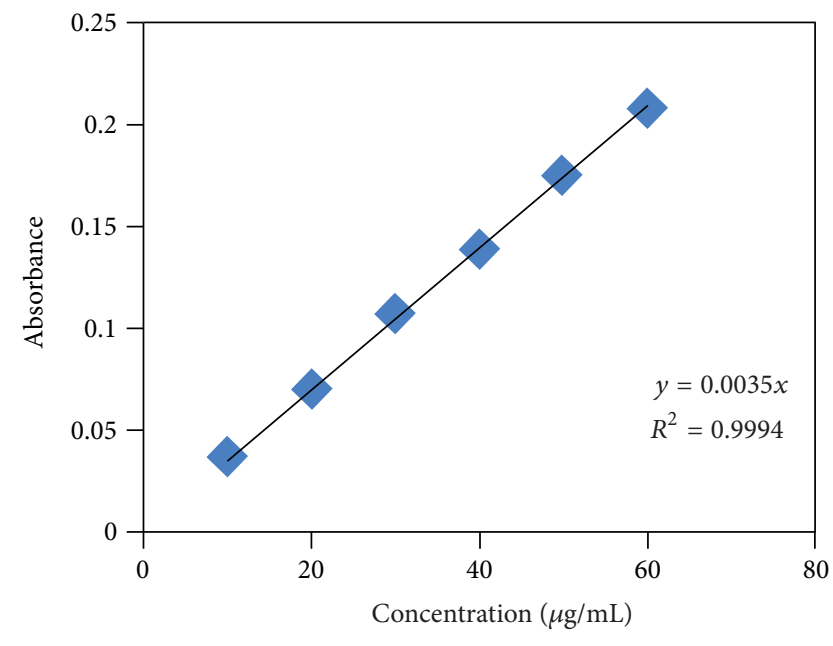

FIgURE 3: Calibration curve of ART.

respectively. Table 2 summaries the optical characteristics of both drugs.

2.4. Determination of Absorptivity Coefficients at Analytical Wavelengths. The absorptivity coefficients for the two drugs were determined at both the selected wavelengths. The values obtained as the mean of six independent determinations were used for forming the simultaneous equations.

The simultaneous equations formed were as follows:

$$
A_{1}=6.95 \times C_{1}+4.2 \times C_{2}
$$

at $222 \mathrm{~nm}$ (For Mefloquine)

$$
A_{2}=3.5 \times C_{1}+6.58 \times C_{2}
$$

at $240 \mathrm{~nm}$ (For Artesunate), where $A_{1}$ and $A_{2}$ are the absorbance of sample solution at $222 \mathrm{~nm}$ and $240 \mathrm{~nm}$, respectively, and $C_{1}$ and $C_{2}$ are the concentrations of Mefloquine and Artesunate, respectively, (in $\mathrm{gL}^{-1}$ ) in the sample solution. By solving the two simultaneous equations, the concentration of mefloquine $\left(C_{1}\right)$ and artesunate $\left(C_{2}\right)$ in sample solutions can be obtained.

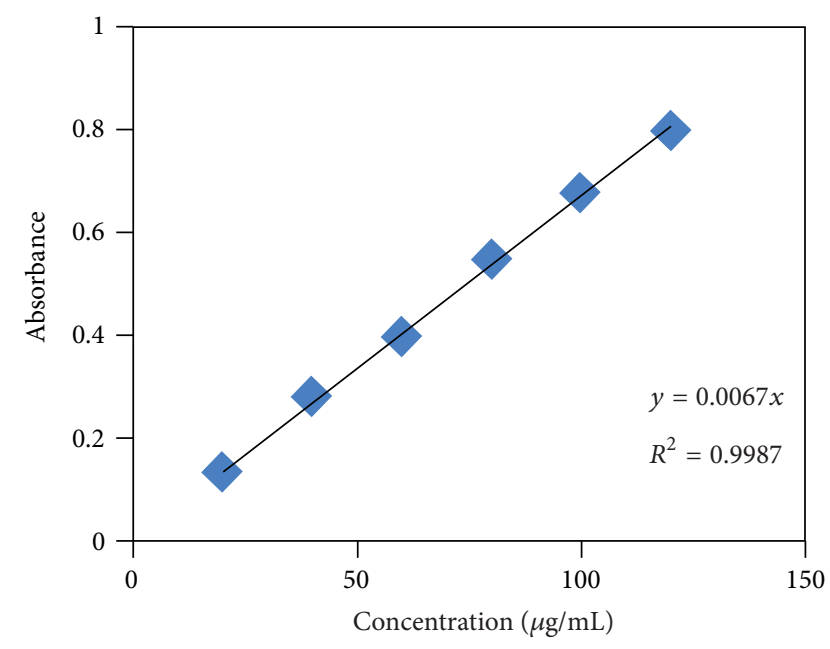

FIGURE 4: Calibration curve of MEF.

2.5. Analysis Standard Containing ART and MEF. The method was checked by analyzing a solution containing known concentration of both drugs. The mixed standards in the Beer-Lambert's range for each drug in the ratio of $1: 2$ containing 10,30 , and $60 \mu \mathrm{g} / \mathrm{mL}$ of ART and 20, 60 , and $120 \mu \mathrm{g} / \mathrm{mL}$ of $\mathrm{MEF}$, respectively, were prepared by diluting appropriate volumes of standard stock solutions. The scanning of mixed standard solutions was carried out in the range of $400 \mathrm{~nm}$ to $200 \mathrm{~nm}$ in spectrum mode (Table 3). The absorbance of mixed standard solutions was measured at $240 \mathrm{~nm}$ and $222 \mathrm{~nm}$. The concentrations of ART and MEF present in mixed standards were calculated using (1) and (2) (Table 4). The results obtained were good and hence the method was applied to the marketed tablet formulation.

2.6. Procedure for Analysis of Tablet Formulation. Twenty tablets were weighed accurately; the average weight was determined and then triturated to a fine powder. A quantity equivalent to $100 \mathrm{mg}$ of ART and $200 \mathrm{mg}$ of MEF was weighed and transferred to a $100 \mathrm{~mL}$ volumetric flask containing 
TABLE 5: Results of marketed tablet formulation.

\begin{tabular}{|c|c|c|c|c|c|c|}
\hline \multirow{2}{*}{ Sr. no. } & \multicolumn{2}{|c|}{ Label claim (mg/tab) } & \multicolumn{2}{|c|}{ Amount found (mg/tab) } & \multicolumn{2}{|c|}{$\%$ of Label claim } \\
\hline & ART & MEF & ART & MEF & ART & MEF \\
\hline (1) & 100 & 200 & 99.63 & 198.72 & 99.63 & 99.36 \\
\hline (2) & 100 & 200 & 99.70 & 199.44 & 99.70 & 99.72 \\
\hline (3) & 100 & 200 & 100.02 & 198.88 & 100.02 & 99.44 \\
\hline (4) & 100 & 200 & 99.91 & 199.96 & 99.91 & 99.98 \\
\hline (5) & 100 & 200 & 99.86 & 198.96 & 99.86 & 99.48 \\
\hline \multirow[t]{4}{*}{ (6) } & 100 & 200 & 99.57 & 200.36 & 99.57 & 100.18 \\
\hline & & & & Mean & 99.78 & 99.69 \\
\hline & & & & SD & 0.1754 & 0.3287 \\
\hline & & & & $\%$ RSD & 0.1757 & 0.3297 \\
\hline
\end{tabular}

Formulation: Falcigo Plus (Zydus Cadila Pharmaceutical Ltd., Ahmadabad).

TABLE 6: Results of recovery studies.

\begin{tabular}{|c|c|c|c|c|c|c|c|c|}
\hline \multirow{2}{*}{ Level of (\%) recovery } & \multicolumn{2}{|c|}{ Amount present(mg/tab) } & \multicolumn{2}{|c|}{ Amount of standard added (mg) } & \multicolumn{2}{|c|}{ Total amountrecovered(mg) } & \multicolumn{2}{|c|}{ \% Recovery ${ }^{*}$} \\
\hline & ART & $\mathrm{MEF}$ & ART & MEF & ART & MEF & ART & MEF \\
\hline 80 & 100 & 200 & 80 & 160 & 179.28 & 359.24 & 99.59 & 99.79 \\
\hline 100 & 100 & 200 & 100 & 200 & 199.8 & 398.46 & 99.89 & 99.61 \\
\hline \multirow[t]{4}{*}{120} & 100 & 200 & 120 & 240 & 220.6 & 436.90 & 100.26 & 99.29 \\
\hline & & & & & & $\%$ Mean & 99.91 & 99.56 \\
\hline & & & & & & SD & 0.2740 & 0.2067 \\
\hline & & & & & & RSD & 0.2742 & 0.2076 \\
\hline
\end{tabular}

${ }^{*}$ Each value is the mean of three observations.

$70 \mathrm{~mL}$ methanol, and the contents were sonicated for $20 \mathrm{~min}$ with methanol to dissolve the active ingredients. Volume was made up to $100 \mathrm{~mL}$ with methanol and filtered through Whatman filter paper no. 41 to give the stock solution containing $1000 \mu \mathrm{g} / \mathrm{mL}$ of ART and $2000 \mu \mathrm{g} / \mathrm{mL}$ of MEF. Various dilutions of the tablet stock solutions were scanned and the absorbance of these solutions were measured at $240 \mathrm{~nm}$ and $222 \mathrm{~nm}$, respectively, and the concentrations of the two drugs in the sample solutions were calculated using (1) and (2). The analysis procedure was repeated six times. The results of marketed tablet formulation are given in Table 5 .

2.7. Recovery Studies. Recovery studies were carried out at three levels that is, 80,100 , and $120 \%$ of the label claim of the Tablet formulation as per ICH guidelines $[3,4]$.

To perform recovery studies at $80 \%$ of the test concentration, sample containing $100 \mathrm{mg}$ of ART and $200 \mathrm{mg}$ of MEF was weighed and transferred to a $100 \mathrm{~mL}$ volumetric flask. To it, $80 \mathrm{mg}$ of standard ART and $160 \mathrm{mg}$ of standard MEF was added, the mixture was mixed thoroughly. Then $70 \mathrm{~mL}$ of methanol was added and the contents were sonicated for $20 \mathrm{~min}$ with methanol to dissolve the active ingredients, and the volume was made up to $100 \mathrm{~mL}$ with methanol and filtered through Whatman filter paper no. 41.

Similarly, to perform recovery studies at $100 \%$ of the test concentration, tablet powder containing $100 \mathrm{mg}$ of ART and $200 \mathrm{mg}$ of MEF was weighed. To it, $100 \mathrm{mg}$ of standard ART and $200 \mathrm{mg}$ of standard MEF was added and at $120 \%$ level,
$120 \mathrm{mg}$ of standard ART and $240 \mathrm{mg}$ of standard MEF was added to the tablet powder equivalent to $100 \mathrm{mg}$ of ART and $200 \mathrm{mg}$ of MEF. Then $70 \mathrm{~mL}$ of methanol was added, the contents were sonicated for $20 \mathrm{~min}$ with methanol to dissolve the active ingredients, and the volume was made up to $100 \mathrm{~mL}$ with methanol and filtered through Whatman filter paper no. 41.

From the stock solutions prepared at each level, suitable aliquots were pipetted out and diluted to $10 \mathrm{~mL}$ with methanol and were analysed as per the procedure for tablet formulations. The results of the recovery studies were also validated statistically. The results of recovery studies are given in Table 6.

2.8. Precision of Method. Precision of the method was verified by using stock solutions in the ratio of $1: 2$ containing $60 \mu \mathrm{g} / \mathrm{mL}$ ART and $120 \mu \mathrm{g} / \mathrm{mL}$ of MEF. System repeatability was done by repeating the assay three times of six replicate dilutions of the same concentration after every two hours on the same day for intraday precision. Interday precision was carried out by performing the assay of six sample sets after 24 hours and 48 hours. The results of intermediate precision are given in Table 7 .

\section{Conclusion}

The novel method for simultaneous estimation of ART and MEF was developed using alcoholic solubilization technique. ART and MEF follow Beer-Lambert's law in range 
TABLE 7: Results of intermediate precision.

\begin{tabular}{lccc}
\hline Formulation & Parameter & $\begin{array}{c}\text { Intraday } \\
\text { precision }\end{array}$ & $\begin{array}{c}\text { Interday } \\
\text { precision }\end{array}$ \\
\hline \multirow{2}{*}{ ART } & Mean & 99.59 & 99.69 \\
& SD & 0.3177 & 0.3723 \\
MEF & \% RSD & 0.3190 & 0.3734 \\
\hline \multirow{3}{*}{ Mean } & 100.21 & 99.49 \\
& SD & 0.5657 & 0.2502 \\
\hline
\end{tabular}

of $10-60 \mu \mathrm{g} / \mathrm{mL}$, and $20-120 \mu \mathrm{g} / \mathrm{mL}$ shows ART and MEF can be estimated in Methanol. Commercial formulation containing ART and MEF were analyzed by proposed method Mean assay values in Falcigo Plus were found to be $99.78 \pm$ 0.1754 and $99.69 \pm 0.3287$, respectively. The accuracy of method was determined by recovery studies. Pure ART and MEF were added to the preanalyzed tablet powder at three different levels, namely, 80,100 , and $120 \%$ of labeled claims as per the ICH guidelines. Three replicate analyses were carried out at each level. The mean recovery was found to be $99.91 \pm 0.2740 \%$ and $99.56 \pm 0.2067 \%$ in Falcigo Plus samples, respectively, indicating that the method has required accuracy and there was no interference from the common excipients present in tablets. The RSD value below $2 \%$ indicated that the method has required precision. LOD and LOQ values at 240 and 222 were found to be 0.54 and $0.45 \mu \mathrm{g} / \mathrm{mL}$ and 1.79 and $1.48 \mu \mathrm{g} / \mathrm{mL}$, respectively.

Thus, the developed method was simple, accurate, and precise and can be used for routine analysis of ART and MEF in pharmaceutical preparation.

\section{Acknowledgments}

The authors are thankful to Cipla. Ltd. and Macleoids Ltd. for providing them with the gift sample of the pure drug and to the Director School of Pharmacy, S. R. T. M. University, Nanded, MS, India, for providing research facilities.

\section{References}

[1] World Health Organization, Antimalarial Drug Combination Therapy. Report of a WHO Technical Consultation, WHO, Geneva, Switzerland, 2001.

[2] D. N. Shetty, B. Narayana, and S. Samshuddin, "Sensitive methods for the spectrophotometric determinations of some antimalarial drugs," Journal of Chemical and Pharmaceutical Research, vol. 4, no. 3, pp. 1647-1653, 2012.

[3] ICH, Q2A Validation of Analytical Procedures: Consensus Guidelines; ICH Harmonized Tripartite Guidelines, 1994.

[4] ICH, Q2B Validation of Analytical Procedures: Methodology, Consensus, Consensus Guidelines; ICH Harmonized Tripartite Guidelines, 1996. 

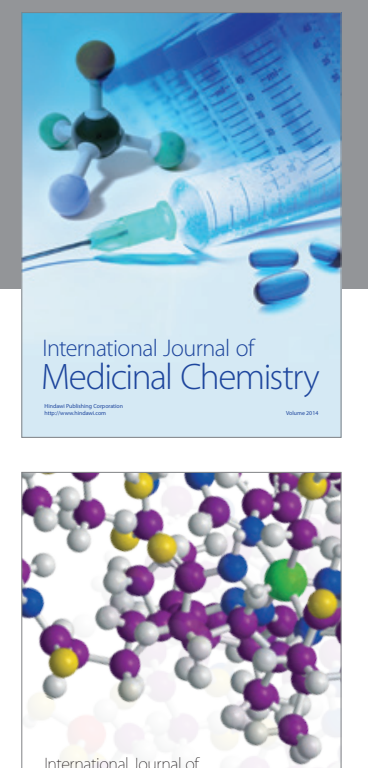

\section{Carbohydrate} Chemistry

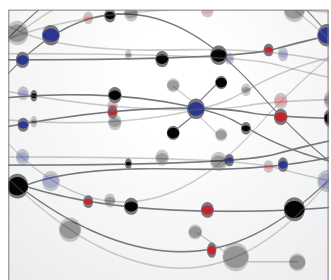

The Scientific World Journal
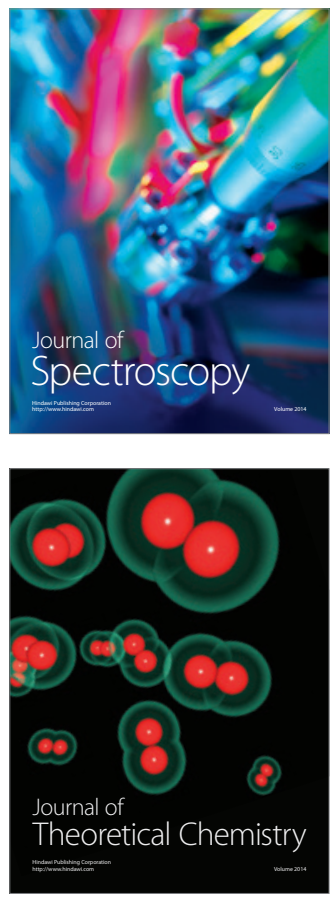
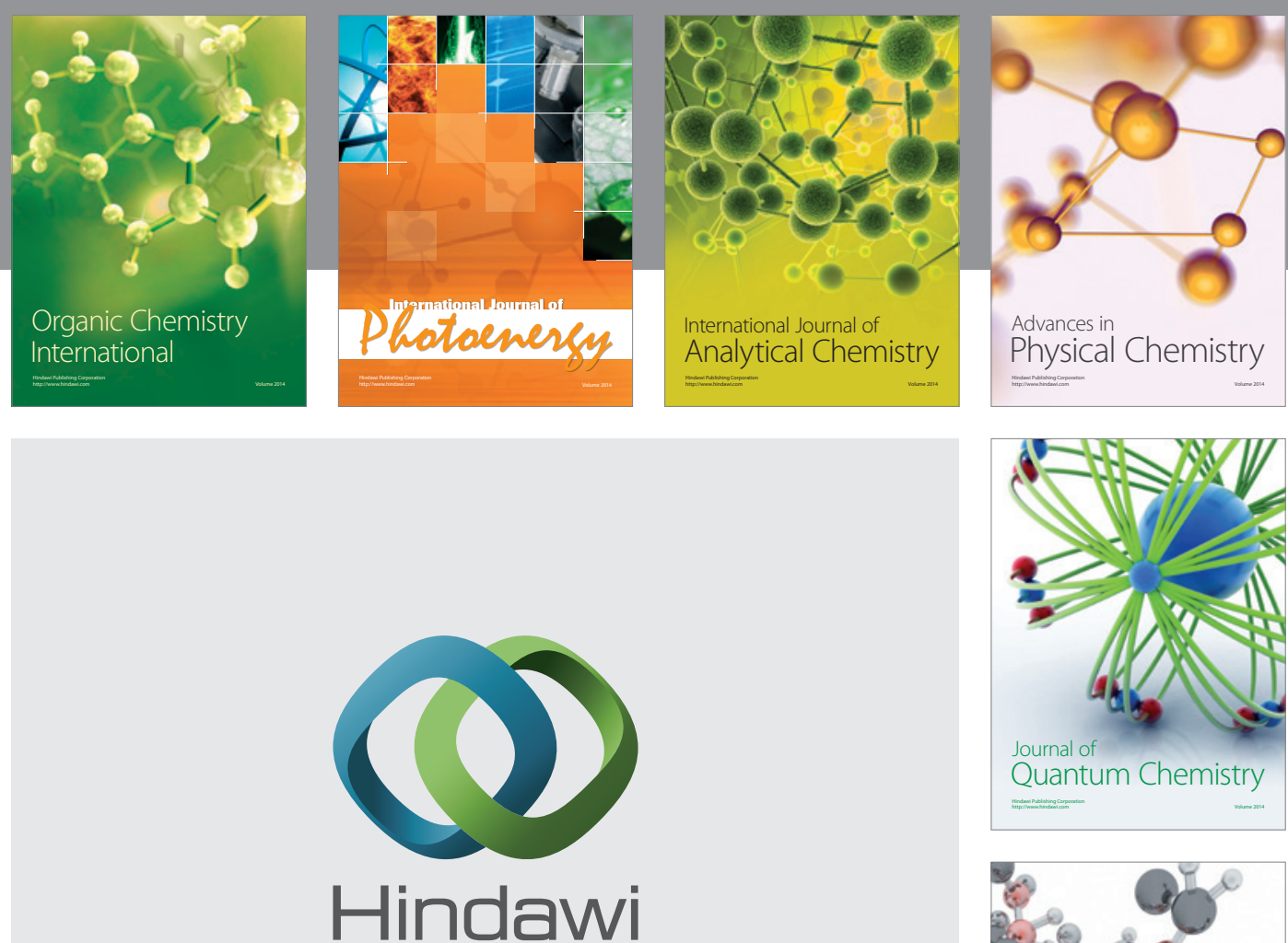

Submit your manuscripts at

http://www.hindawi.com

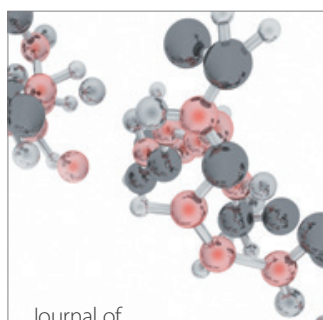

Analytical Methods

in Chemistry

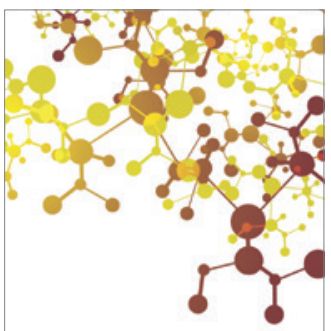

Journal of

Applied Chemistry

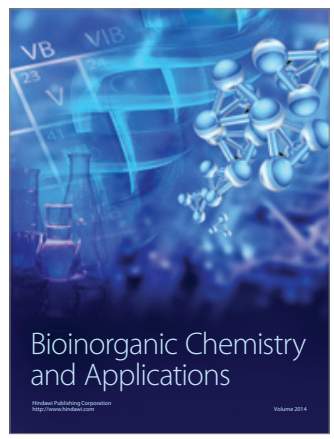

Inorganic Chemistry
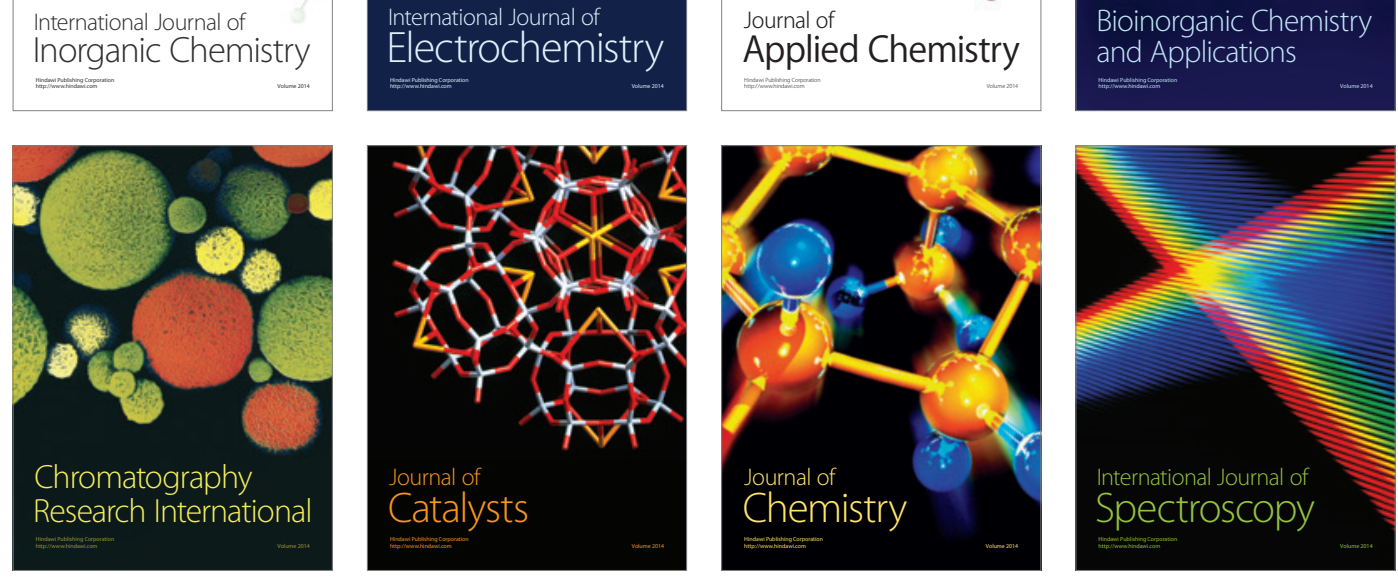